\title{
EDITORIAL
}

Versão original

DOI: http://dx.doi.org/10.1590/So034-759020200501

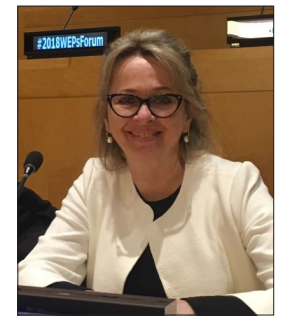

MARIA JOSÉ TONELLI Editora-chefe

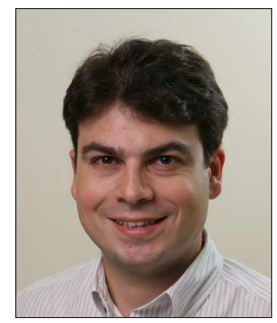

FELIPE ZAMBALDI Editor-adjunto

\section{O FUTURO DO TRABALHO E O TRABALHO DO(A) PESQUISADOR(A)}

A seção Perspectivas desta edição discute o futuro do trabalho e traz o ponto de vista de Gazi Islam e Wilson Amorim. Desde o clássico artigo "Bringing work back in", de S. Barley e G. Kunda (2001), o tema aparece e desaparece dos estudos sobre gestão. Com a pandemia, o tema voltou à cena, com a tecnologização das casas para a produtividade no trabalho (para aqueles que podem, evidentemente), o desaparecimento das fronteiras entre casa e trabalho, o aumento do desemprego, a reorganização dos sistemas de gestão das empresas, entre inúmeros outros fenômenos que experimentamos atualmente. A intensificação de trabalhos por contrato, já antecipada por Barley e Kunda (2004), volta a ter protagonismo (Pereira, 2020). Mas, além das mudanças na organização do trabalho e da gestão de pessoas, enfrentamos também dificuldades para fazer pesquisa em torno do tema (Oltramari, 2020).

O que significa fazer pesquisas sobre o trabalho e o que significa o trabalho do(a) pesquisador(a) hoje? Em entrevista para o jornal O Estado de S. Paulo, o presidente da Fapesp, Marco Antonio Zago (2020), afirma que o “mundo gira por causa do progresso científico e não da economia" e que o corte de verbas para pesquisa não tem impacto imediato, mas traz graves consequências para o País no horizonte de 10 anos. A redução dos recursos para pesquisa não é uma ação sem consequências. Se juntarmos a falta de recursos com as dificuldades práticas de realizar pesquisas sobre o trabalho (e muitos outros fenômenos vitais em Administração de Empresas), podemos vislumbrar o futuro do trabalho e do trabalho dos(as) pesquisadores(as) no País.

Fazer ciência dá trabalho, mas gera resultados. Entre eles, os artigos que são apresentados nesta edição: "Reinventando o cotidiano: Análise de práticas de consumo sob a ótica de Certeau”, de Fernanda Guarnieri e Francisco Giovanni David Vieira, “Concentração acionária, conselho de administração e remuneração de executivos”, de Maria Rafaela de Oliveira Freitas, Gustavo Magno Pereira, Alessandra Carvalho de Vasconcelos e Márcia Martins Mendes De Luca, “Portfólio de alianças e desempenho inovador da indústria brasileira”, de Frederico G. P. Moreira e Ana L. V. Torkomian e Herick Moralles, e "Más (boas) notícias e postergação (antecipação) de divulgação de demonstrações financeiras”, de Anderson Brito Vivas, Felipe Ramos Ferreira e Fábio Moraes da Costa; na seção Perspectivas, "The future(s) of work", de Gazi Islam, e "Futuro do trabalho no Brasil: Cuidar das instituições”, de Wilson Aparecido Costa de Amorim; já na seção Resenha, "Inteligência artificial, trabalho e produtividade”, de Rodrigo Brandão, e "Violência e potência: Crítica do racismo e utopia antirracista”, de Pedro Jaime; por fim, na seção Indicação Bibliográfica, recomendações de livros sobre “Questão racial no Brasil”, sugeridos pelo professor Pedro Jaime.

Desejamos a todos que participam da comunidade científica em Administração de Empresas que possam continuar com suas pesquisas e com o ensino, que geram não só artigos científicos mas também a capacidade de pensar e de resolver problemas complexos como os que vivemos atualmente.

Boa leitura!

Maria José Tonelli ${ }^{1}$ | ORCID: 0000-0002-6585-1493

Felipe Zambaldi ${ }^{1}$ | ORCID: 0000-0002-5378-6444

${ }^{1}$ Fundação Getulio Vargas, Escola de Administração de Empresas de São Paulo, São Paulo, SP, Brasil

\section{REFERÊNCIAS}

Barley, S., \& Kunda, G. (2001). Bringing work back in. Organization Science, 12(1).

Barley, S., \& Kunda, G. (2004). Gurus, hired guns, and warm bodies: Itenerant experts in a knowledge economy. Princeton: Princeton University Press.

Oltramari, A. (2020, setembro 19). Os desafios da pesquisa sobre o trabalho na atualidade. Nuevo Blog. Recuperado de http:// nuevoblog.com/2020/09/19/os-desafios-da-pesquisa-sobre-o-trabalho-na-atualidade/

Pereira, J. L., Filho. (2020). O futuro do trabalho e novos modelos de gestão de pessoas (Tese de doutorado, FGV - EAESP).

Zago, M. A. (2020). O Estado de S. Paulo. Entrevista. Recuperado de https://sustentabilidade.estadao.com.br/noticias/geral,mundo-gira-por-causa-do-progresso-cientifico-diz-presidente-da-fapesp,70003445941 